\title{
Air frying a new technique for produce of healthy fried potato strips
}

\author{
Shaker, M. Arafat \\ Oils \& Fats Research Department, Food Technology Research Institute, Agriculture Research Centre, Giza, Egypt
}

Email address:

dr_shakerarafat@yahoo.com

To cite this article:

Shaker, M. Arafat. Air Frying a New Technique for Produce of Healthy Fried Potato Strips. Journal of Food and Nutrition Sciences. Vol. 2, No. 4, 2014, pp. 200-206. doi: 10.11648/j.jfns.20140204.26

\begin{abstract}
The objective of this work was carried out to study the evaluate air frying process as a new technique for frying process. The Potato strips were fried in both air-frying machines (Tefal Actifry) at $180^{\circ} \mathrm{C} \pm 5^{\circ} \mathrm{C}$ for 40 min and traditional frying process at $180^{\circ} \mathrm{C}$ for $40 \mathrm{~min}, 6 \mathrm{~min} / \mathrm{batch}$. After frying, the moisture and oil uptake were determined. Changes in some physico-chemical properties of oil extracted from fried potato strips by the two frying process were determined. Also, organoleptic evaluation of fried potato strips by using air and traditional frying process were evaluated by tasters. Results indicated that the moisture content and oil uptake in fried potato strips by air frying were significantly lower than fried potato strips by traditional frying. Changes in some physico-chemical properties (free fatty acid, peroxide value, polar, polymer and oxidized fatty acids contents) of oil extracted from fried potato were significantly higher in traditional frying than air frying. Organoleptic attributes of fried potato strips by air frying surprised on fried potato strips for traditional frying. Generally, the air frying was more suitable for frying process and produce healthy fried foods than other traditional frying method.
\end{abstract}

Keywords: Air Frying, Polar Compound, Oil Uptake, Moisture Content, Potato Strips

\section{Introduction}

Deep-fat frying can be defined as the process of drying and cooking through contact with hot oil [1 and 2]. In deepfat fried products, the sensory aspects should be addressed to meet consumer demand. High heat transfer rates are largely responsible for the development of the desired sensorial properties in fried products [3]. Dehydration in hot oil at temperatures between $160^{\circ} \mathrm{C}$ and $180^{\circ} \mathrm{C}$ is characterized by very high drying rate that is critical for ensuring favorable structural and textural properties of the final product [4].

Frying time, food surface area, moisture content of food, types of breading or battering materials, and frying oil influence the amount of absorbed oil to foods [5]. The oil contents of potato chips, corn chips, tortilla chips, doughnuts, French fries, and fried noodle (ramyon) were in the range $33 \%-38 \%, 30 \%-38 \%, 23 \%-30 \%, 20 \%-25 \%$, and $10 \%-15 \%$ [6], and $14 \%$ [7], respectively. The absorbed oil tends to accumulate on the surface of fried food during frying in most cases [8] and moves into the interior of foods during cooling.
In recent years, consumer's preference is to consumer low fat and fat-free products has been the driving force of this food industry to produce lower oil content fried potatoes that still retain the desirable texture and flavor. [9] introduced the criterion UR, which expresses the ratio between the amount of oil uptake and water removed. Different means to reduce oil uptake in fried potatoes have been reported. For instance, vacuum frying may be an option for fried potatoes with low oil content and desired texture and flavor characteristics [10 and 11]. Soaking potato strips in $\mathrm{NaCl}$ solutions reduced oil uptake in French fries after frying [12]. Pre-drying of potatoes is also a common way to reduce fat uptake in fried potatoes [13 and 14]. The blanching step previous to frying in potato chip processing improves the color and texture, and could reduce in some cases the oil uptake by gelatinization of the surface starch [15].

Frying can be considered a dehydration operation in which a simultaneous heat and mass transfer occurs giving two counter-fluxes i.e., a water outlet from the food to the 
hot oil and an oil inlet by the food [16], leading to series of physical and chemical changes in the final product. Despite undergoing the large gain of oil during processing of the product, frying is a widely used domestic and industrial cooking technique because of its ability to generate, in the final product, a combination of texture, color, and unique flavor that makes it a more palatable and desirable food for the consumer [17]. Among fried products, the most widely known and consumed are the ones derived from potatoes such as chips and French fries, followed by the better products and the ones of direct consumption as snacks [18].

Many studies showed that excessive consumption of fried products can lead to serious health risks such as cardiovascular disease, hypertension, diabetes, cancer and obesity [19]. These facts, together with the current trend of society to consume fat-free products, have forced the industry in general, and chips industry in particular, to focus its efforts on developing alternative methods of frying that lead to products with low oil content but with the same features of flavor, color, and texture that make them so prized by consumers. In this sense, many strategies have been proposed to reduce oil content in fried products such as low pressure [20 and 21] or microwave application [22] or different pretreatments such as blanching, freezing [23], or predrying [24]. However, these alternatives do not always mimic the sensory features of conventional fried products or the cost is higher than conventional frying. The average world prices for sunflower seed oil were 1046.25 \$US/ton [25]. Hot air frying is a new technique to get fried products through direct contact between an external emulsion of oil droplets in hot air and the product into a frying chamber. The product is constantly in motion to promote homogeneous contact between both phases. In this way, the product is dehydrated and the typical crust of fried products gradually appears. The amount of oil used is significantly lower than in deep oil frying giving, as a result, very low fat products. Today, it is possible to find, on the market, home equipment designed from this principle to obtain low-fat fried products. However, there are no references or scientific publications that describe the mechanisms and kinetics of mass transfer phenomena and volume changes taking place during hot air frying. Therefore, a better scientific understanding of this technique is necessary in order to extend its application either to fast food restaurants or industries.

The aim of this study was to investigate the effect of airfrying process on moisture and oil contents and sensory evaluation of fried potato strips compared with traditional deep-fat frying. Also, study the changes in physicochemical properties of oil extracted from potato strips after frying.

\section{Materials and Methods}

\subsection{Materials}

Potatoes (Solanum tuberosum L., Spunta variety) and sunflower oil purchased from local market. The initial moisture content of potato was in range of $77.25 \%$. Peroxide and acid values of the sunflower oil were 0.75 active oxygen peroxides per kilogram of oil and $0.09 \mathrm{mg}$ $\mathrm{KOH}$ per gram of oil respectively.

\subsubsection{Chemicals}

All chemicals used for the analysis were of analytical grade and bought from Sigma Chemical Company, (ST. Louis, US).

\subsection{Methods}

\subsubsection{Preparation of Potatoes Strips}

Potatoes were sorted, washed, hand-peeled and cut by means of a manual operated potato-cutting into strips $(8 \times 8$ $\mathrm{x} 60 \mathrm{~mm}$ ), then soaked in $\mathrm{NaCl}$ solution and dried potato strips using tissues before frying.

\subsection{Frying Process}

\subsubsection{Traditional Frying Process}

Frying was carried out in a thermostatically temperaturecontrolled fryer (Philips comfort, Germany) having a capacity of 2 L oil by 200 gram of potato, i.e., a potato-tooil ratio of $1: 20(\mathrm{w} / \mathrm{v})$, according to the capacity of the equipment. The potato strips were fried in sunflower oil at $180^{\circ} \mathrm{C} \pm 5^{\circ} \mathrm{C}$ for $40 \mathrm{~min}$., $6 \mathrm{~min} / \mathrm{batch}$. All fried samples were allowed to cool at room temperature; then analyzed for its oil content by Soxhlet apparatus. All experiments were run in triplicates and the present results are the average of the obtained results.

\subsubsection{Air Frying Process}

Air frying equipment (Model: SERIE 001 Actifry, Tefal, France) with a nominal power: 1.400 W. Air frying experiments, $0.03 \mathrm{~kg}$ of oil by kilogram of potato at ratio (0.03:1) was added on potato strips for $40 \mathrm{~min}$, according to the specifications of the equipment. A constant frying temperature was confirmed by means of two PT-100 temperature sensors (model: TF101K) located at the top and the bottom of each fryer. Samples were immersed in the oil in deep oil frying and on surface of foods in air frying when the initial frying temperature of $180^{\circ} \mathrm{C}$ was achieved.

\subsection{Chemical Composition of Fresh and Fried Potatoes}

Moisture and oil contents, reducing sugars in fresh and fried potato strips were determined according to [27].

\subsection{Extraction of Oil}

Fried potato strips oil was extracted by Soxhlet Method, [26]. A total of $50 \mathrm{~g}$ dried fried potato strips sample was weighted and extracted with n-hexane in a Soxhlet apparatus at a condensation rate of 5 or 6 points per second for 4 hours with $300 \mathrm{ml}$ of hexane at a temperature of $70^{\circ} \mathrm{C}$. The solvent was evaporated to dryness using a rotary evaporator at $40^{\circ} \mathrm{C}$. 


\subsection{Quality Assurance Tests for Non Fried and Fried Sunflower Oil}

Refractive index, acid value, peroxide value and iodine value were determined according to [26]. Petroleum etherinsoluble oxidized fatty acids and insoluble polymer contents of sunflower oil samples were determined according to the methods of [27]. Polar and non-polar components in sunflower oil samples were measured by column chromatography according to the method described by $[28]$.

\subsection{Oil Stability}

Oxidative stability was evaluated by the Rancimat method [29]. Stability was expressed as the oxidation induction time (h), measured with the Rancimat 679 apparatus (Metrohm Co., Herisou, Switzerland) using an oil sample of $5.00 \mathrm{~g}$ heated to $100^{\circ} \mathrm{C} \pm 2^{\circ} \mathrm{C}$ with an air flow rate of $20 \mathrm{l} / \mathrm{h}-1$.

\subsection{Organoleptic Evaluation of Fried Potato Chips}

Sensory evaluation was performed on potato strips fried in sunflower oil by using air and traditional frying $180^{\circ} \mathrm{C} \pm$ $5^{\circ} \mathrm{C}$. Prior to the sensory tests, the panelists (twenty persons) were trained to evaluate the attributes of the strips produced in this study and become proficient. The potato strips samples were rated on a 10 point scale $(1,2$ : bad; 3,4 : poor; 5,6: fair; 7,8: good and 9,10 excellent). The potato strips from each treatment, placed randomly in codified plates with three-digit code, were served to each panelist. Judges were placed in different places to avoid communication during the evaluation and asked to score strips for taste, texture, appearance, crispiness, color, odor and overall acceptability [30].

\subsection{Statistical Analysis}

A one-way ANOVA followed by Duncan's multiple range test (DMRT) were performed using SPSS 11.00 [31] to analyze and compare the data. Results were presented for mean $\pm \mathrm{SD}$ and $\mathrm{P}$ - values $\leq 0.05$ were regarded as statistical significance.

\section{Results and Discussion}

Physico-chemical properties and fatty acid composition of sunflower seed oil: Table 1 presents the physicochemical properties of fresh sunflower oil. The refractive index at $25^{\circ} \mathrm{C}$ and iodine value of sunflower oil were 1.4738 and $123.30(\mathrm{I} / 100 \mathrm{~g})$ respectively. Table 1 includes the free fatty acid, peroxide value, iodine value, polar content, polymer content, oxidized fatty acids, and oxidative stability and the data were $0.09 \%, 0.75,123.30$, $0.08 \%, 0.00 \%, 0.00 \%$ and $7.10 \mathrm{~h}$ respectively. Fatty acid composition of fresh sunflower oil indicates the presence of oleic and linoleic acids at high levels $(53.90 \%)$ followed by oleic acid $(30.80 \%)$. The major saturated fatty acid was palmitic acid (7.70\%) followed by stearic acid (6.50\%). On the other hand, the major unsaturated fatty acids were linoleic acid. The $\mathrm{C}_{18: 3}, \mathrm{C}_{20: 0}$ and $\mathrm{C}_{22: 0}$ were detected in trace amounts in sunflower oil. These results are in agreement with [32].

Table 1. Physico-chemical properties and fatty acid composition (\%) of sunflower seed oil.

\begin{tabular}{ll}
\hline Parameter & value \\
\hline Refractive index at $25^{\circ} \mathrm{C}$ & 1.4738 \\
Acid value (mg KOH/g oil) & 0.09 \\
Peroxide value (meq. peroxides /kg oil) & 0.75 \\
Iodine number (I/100g oil) & 123.30 \\
Polar content (\%) & 0.08 \\
Polymer content (\%) & 0.00 \\
Oxidized fatty acids (\%) & 0.002 \\
Oxidative stability (hr) & 7.10 \\
Fatty acid composition: & \\
$\mathrm{C}_{16: 0}$ & 7.70 \\
$\mathrm{C}_{18: 0}$ & 6.50 \\
$\mathrm{C}_{18: 1}$ & 30.80 \\
$\mathrm{C}_{18: 2}$ & 53.90 \\
$\mathrm{C}_{18: 3}$ & 0.20 \\
$\mathrm{C}_{20: 0}$ & 0.50 \\
$\mathrm{C}_{20: 1}$ & 0.20 \\
$\mathrm{C}_{22: 0}$ & 0.20 \\
Total saturated fatty acids & 15.10 \\
Total unsaturated fatty acids & 84.90 \\
\hline
\end{tabular}

Chemical composition of potato strips before and after frying process: Figure 1 shows that the characteristics of potatoes before and after frying. It can seen that potato strips contained $77.25 \%$ and $22.75 \%$ moisture and dry matter contents respectively, before frying process. After frying the significant differences in moisture content were recorded $30.51 \%$ traditional frying and $35.25 \%$ air frying process respectively. On the other hand, the oil content in potato strips after frying results showed that the oil uptake in traditional fried potato strips was $(14.81 \%)$ higher than air frying $(0.0025 \%)$. From the data in same figure, the potato strips contained low reducing sugar content $(0.82 \mathrm{mg} / 100 \mathrm{~g}$ sample) and so it is suitable potato variety to produce fried product with proper yellow color. [33] reported that the water present in the raw material evaporates and is partially replaced by oil during frying process, constituting up to $40 \%$ of the finished product, and consequently influencing its properties. [34] mention that the frying is a process of immersing food in hot oil with a direct contact of air, at a high temperature of $150^{\circ} \mathrm{C}$ to $190^{\circ} \mathrm{C}$. But air frying is a new technique to get fried products through direct contact between an external emulsion of oil droplets in hot air and the product into a frying chamber [35]. From this it is clear that the traditional 
frying significantly increases (at $\mathrm{P} \leq 0.05$ ) the oil uptake in potato strips more than air-frying, because the amount of oil used in air frying is very small, about $3 \%$, but in the traditional frying oil is used as a medium fry up (1:20 w/w) potato: oil. The amount of absorbed oil in fried food was affected by some factors, i, e., frying time, food surface area, moisture content of food, types of breading or battering materials, and frying oil.

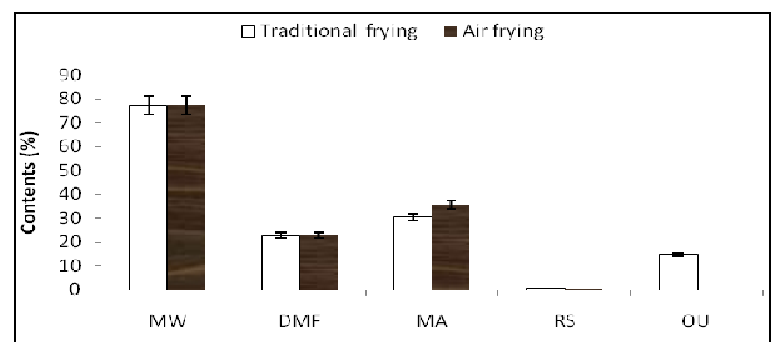

Figure 1. Chemical composition of potatoes strips before and after frying process. Where, $M W=$ moisture before frying, $D M F=$ dry matter before fringy, $M A=$ moisture content after frying, DMA=dry matter after frying, $R S=$ reducing sugar, $O U=$ oil uptake.

The data (values $\pm \mathrm{SE}$ ) are the mean values of three measurements for the same sample.

Changes in some physico-chemical properties of oil extracted from fried potato strips: Results Figure (2) presents that the changes in some physico-chemical properties during traditional and air frying processes. The refractive index at $25^{\circ} \mathrm{C}$ decreased from 1.4738 to 1.4731 for traditional frying and from 1.4738 to 1.4734 for airfrying respectively. The free fatty acid (FFA) content increased from $0.09 \%$ to $0.22 \%$ for traditional frying and from $0.09 \%$ to $0.12 \%$ for air-frying. It has been suggested that production of FFA was the best indicate of fat deterioration during frying and the presence of FFA could be used to monitor the extent of oil abused [36].

On the other hand, the peroxide value (PV) was significantly increased from 0.75 to 2.75 meq. $\mathrm{O}_{2} / \mathrm{kg}$ oil for traditional frying and from 0.75 to 1.22 meq. $\mathrm{O}_{2} / \mathrm{kg}$ oil for air frying. The differences between traditional and air

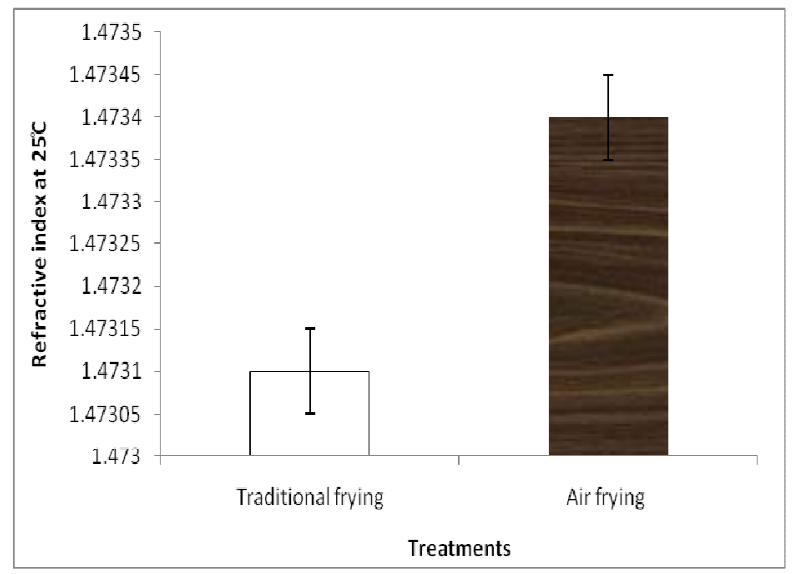

frying in PV values may be due to quantity of oil in traditional frying more higher than amount of quantity of oil in air frying. During the air frying used the traces of oil (3\%) but in traditional oil used $2 \mathrm{~kg}$ for frying $200 \mathrm{~g}$ strips fried every time. The free radicals formed by fatty acids react with oxygen to generate peroxides that enter into a multitude of reactions, producing numerous products, such as aldehydes, ketones, acids, esters and polymerized fat. The extent of reaction depends on the frying temperature, aeration, type of fried or fat and the food that is being fried. The type of food being fried and its interaction with oil has been reported to contribute to the deterioration of frying oil [36].

The changes in polar content (PC) during traditional and air-frying are shown in Figure (2). The determination of PC in frying oil provides the most reliable measure of the extent of oxidative degradation. In this study, initial PC in fresh oil was $0.08 \%$, but after frying the PC increased with frying time at a rate affected by frying temperature. $\mathrm{PC}$ content during frying at $180^{\circ} \mathrm{C} \pm 5^{\circ} \mathrm{C}$ was $(0.71 \%$ for traditional frying and $0.34 \%$ for air-frying) at the end of frying time, which was still below the $24 \%$ oil discard level set in many European countries [37]. On the other hand, the polymer content (PO) in traditional frying was $0.17 \%$ and air-frying was $0.09 \%$, respectively (Figure 2 ). In contrary, oxidized fatty acid (OFA) content was increased after frying to $0.11 \%$ for traditional frying and $0.06 \%$ for airfrying (Figure 2). Polymers formed in deep fat-frying in remarkable are level since the medium is rich in oxygen. [38] reported that oxidized polymer compounds accelerated the oxidation of oil. Polymers accelerate further degradation of the oil, consequently, increased the oil viscosity [39], reduced the heat transfer, produced foam during deep-fat frying, and develop undesirable color in the food. Polymers also cause the high oil absorption to foods. [40] reported that free fatty acids and their oxidized compounds produced off-flavor and make the oil less acceptable for deep-fat frying.

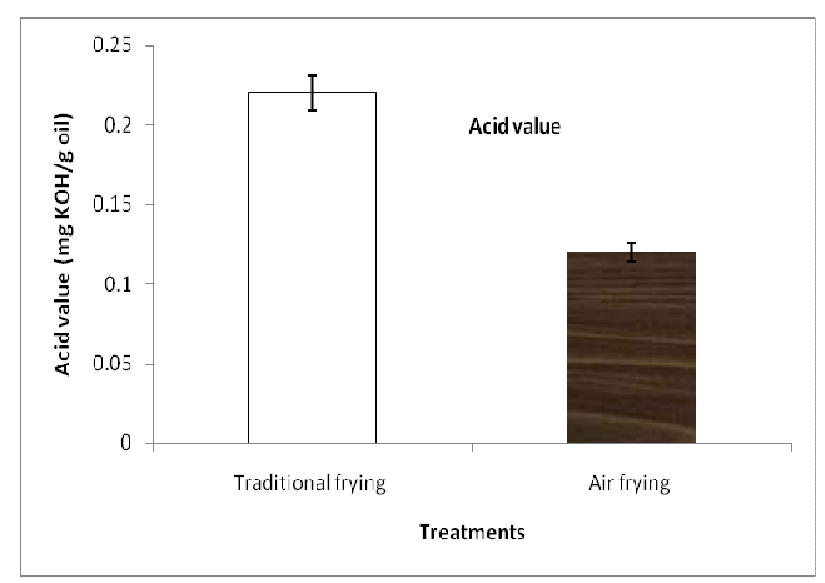



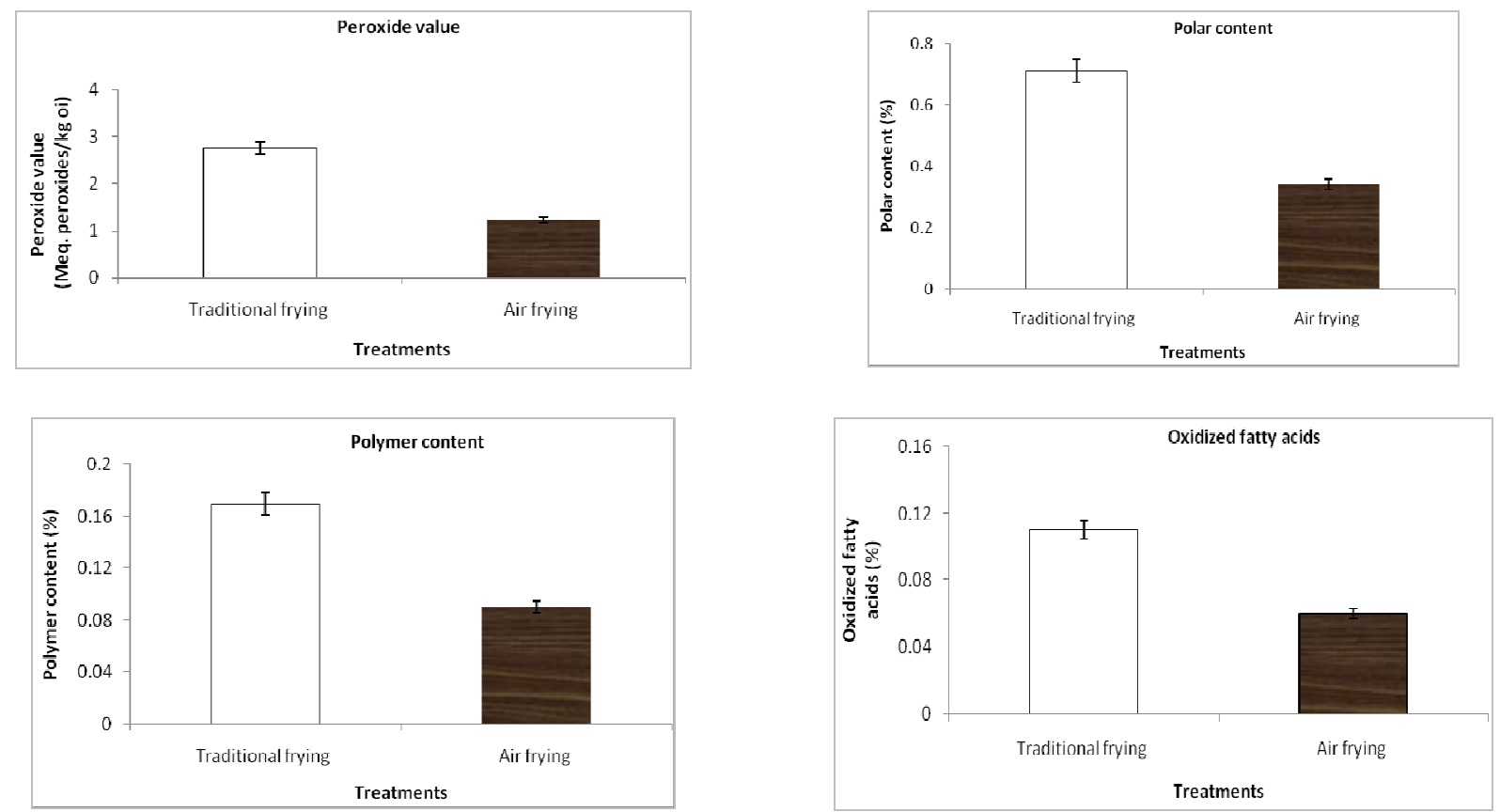

The data (values $\pm \mathrm{SE}$ ) are the mean values of three measurements for the same sample.

Figure 2. Changes in some physico-chemical properties (refractive index, acid value, peroxide value, polar content, polymer content, oxidized fatty acids) of oil extracted from fried potato strips.

Sensory evaluation of fried potato strips: Sensory attributes including taste, appearance, color, odor, crispness, hardness, crispiness, oiliness, and overall acceptability of traditional and air-frying of fried potato strips are shown in Figure 3. Results showed that using air frying process for fried potato strips didn't cause any significant differences on sensory attributes include taste, appearance, odor, crispiness, and overall acceptable compared to the fried potato strips by using traditional frying method. On the other hand, air-fried potato strips surpassed on traditional fried potato strips in other sensory attributes (crispness, hardness and oiliness). The surpassed of air-fried potato strips in hardness and oiliness may be due to the fried potato strips by air frying content on low oil uptake compared to fried potato strips by using traditional frying.

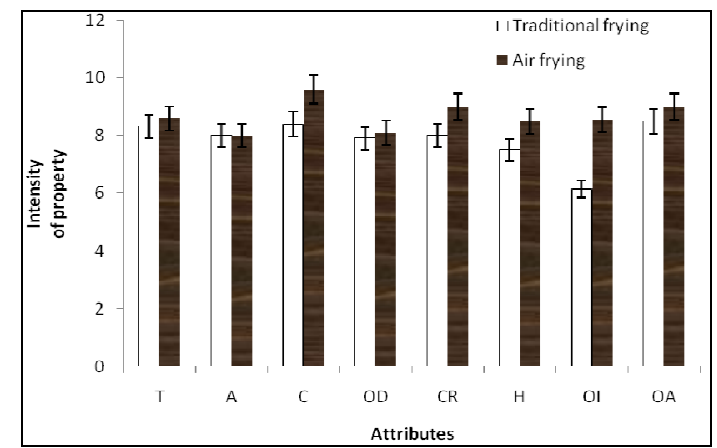

Figure 3. Sensory evaluation of fried potato strips. Where, $T=$ taste, $A=$ appearance, $C=$ color, $O D=$ odor, $C R=$ crispness, $H=$ hardness, $O I=$ oiliness, and $\mathrm{OA}=$ overall acceptable.

The data (values $\pm \mathrm{SE}$ ) are the mean values of three measurements for the same sample.
Cost of sunflower oil used in frying of potato strips under study: The cost of oil used in both frying processes under study is presented in Figure (4). In the air-frying method, the amount of oil used for fried potato strip was $30 \mathrm{~g} / \mathrm{kg}$ potato. In traditional frying method, the mount of used oil was $2 \mathrm{~kg}$ oil for fried potato strips $200 \mathrm{~g}$ every batch. The price of used oil in air frying by Egyptian pound was (0.0025 LE), while, the oil price used in traditional frying (24 LE). The transfer of the price of oil used in both frying process from LE to US $\$$, found that the price of oil used in traditional frying around $(3.44 \$)$, while, the price of oil used in air-frying around $(0.00023 \$)$ Figure 4 . These results illustrated the existence of clear significant differences between the prices of used oil in air-frying compared to traditional frying. Thus, the use of air-frying technique low cost compared to traditional frying Figure 4.

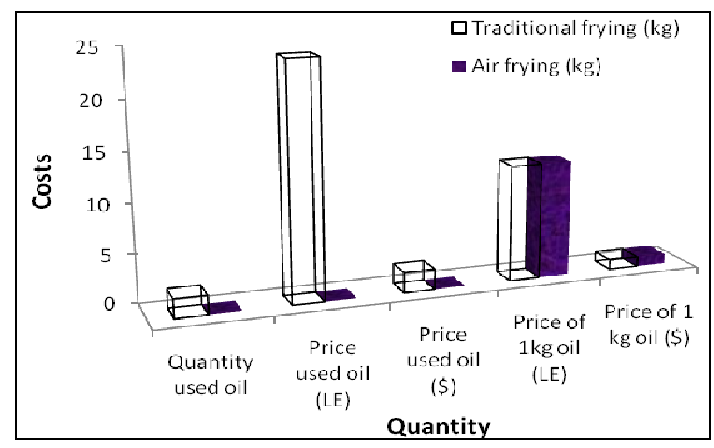

Figure 4. Costs of sunflower oil used in frying of potato strips under study. The data (values $\pm \mathrm{SE}$ ) are the mean values of three measurements for the same sample. 
[41] reported that the availability and cost of oil are important economic factors. Even the best performing frying oil is not beneficial to the business if it is not available in sufficient quantities. The cost of oil is extremely critical for the industry. Most fried snack foods contain $20-40 \%$ oil. Therefore, the snack food company has to minimize the delivered cost of oil at the plant. Sometimes, the procurement department purchases oil from a supplier that does not have good control over their operation. This ends up costing money and goodwill for the snack food company in the long run.

\section{Conclusion}

The present results that the oil uptake was lower under air-frying confirming that this technique can be considered as a healthy one. Thus, this method must be practically process applied to obtain healthy fried foods.

\section{Acknowledgement}

Author would like to acknowledge Prof. Dr. Amany Mohamed Basuny, Professor at Oils \& Fats Dept. Food. Tech. Res. Inst. Agric. Res. Cent. Giza. Egypt, for the support and assistance during this work.

\section{References}

[1] Sahin, S., Sastry, S. K. and Bayindirili, L. (1999): Heat transfer during frying of potato slices. J. LWT., 29: 19-24.

[2] Lesinska, G. and Leszczynski, W. (1989): Potato science technology. Elsevier Science, NY. USA.

[3] Hubbard, L. J. and Farkas, B. E. (1999): A method for determining the convective heat transfer coefficient during immersion frying. J. Food Process Eng. 22: 201-214.

[4] Baumann, B. and Escher, E. (1995): Mass and heat transfer during deep fat frying of potato slices. Rate of drying and oil uptake. J. LWT., 28: 395-403.

[5] Moreira, R. G., Sun, X., and Chen, Y. (1997): Factors affecting oil uptake in tortilla chips in deep-fat frying. J Food Eng 31:485-98.

[6] Moreira, R. G., Castell-Perez, M. E., and Barrufet, M. A. (1999a): Fried product processing and characteristics. In: Deep-fat frying: fundamentals and applications. Gaithersburg, Md.: Chapman \& Hall Food Science Book. P $11-31$.

[7] Choe, E., Kang, W. S., and Chang, Y. S. (1993): Kinds and changes in the amount of flavor compounds formed during storage of the ramyon. Korean J. Food Sci. Technol. 25:526.

[8] Moreira, R. G., Castell-Perez, M. E., and Barrufet, M. A. (1999b): Oil absorption in fried foods. In: Deep-fat frying; fundamentals and applications. Gaithersburg, Md.: Chapman\& Hall Food Science Book. P 179-221.

[9] Pinthus, E. J., Weinberg, P. and Saguy, I. S. (1993): Criterion for oil uptake during deep - fat frying. J. Food Sci. 58: 204205 .

[10] Garayo, J. and Moreira, R. (2002): Vacuum frying of potato chips, J. Food Eng. 55: 181-191.

[11] Basuny, A. M. M., Shaker, A. M., and Azza, A. A. (2012): Vacuum frying: An alternative to obtain high quality potato chips and fried oil. Global Advanced Research Journal of Food Science and Technology, 1(4):058-065.

[12] Bunger, A., Moyano, P. and Rioseco, V. (2003): $\mathrm{NaCl}$ soaking treatment for improving the quality of French-fried potatoes. Food Research Int. 36: 161-166

[13] Krokida, M. K., Oreopolou, V., Maroulis, Z. B. and Marinos-Kouris, D. (2001): Deep fat frying of potato stripsquality issues. J. Drying Tech. 19: 879-935.

[14] Rubnov, M. and Saguy, I. S. (1997): Fractal analysis and crust water diffusivity of a restructured potato product during deep-fat frying. J. Food Sci. 62: 135-137.

[15] Califano, A. N. and Calvelo, A. (1987): Adjustment of surface concentration of reducing sugars before frying of potato strips. J. Food Proc. and Preser, 12: 1-9.

[16] Krokida, M. K., Oreopolou, V., and Maroulis, Z. B. (2000): Water loss and oil uptake as a function of frying time. Journal of Food Engineering, 44: 39-46.

[17] Mestdagh, F., De Wilde, T., Fraselle, S., Govaert, Y., Ooghe, W. Degroodt, J. M., Verhe, R., Van Peteghem, C. and De Meulenear, B. (2008): Optimization of the blanching process to reduce acrylamide potatoes. LWT-Food Science and Technology, 41(9): 1648-1654.

[18] Clark, J. P. (2003): Happy birthday, potato chips! And other snack development. Food Technology, 12, 1-9.

[19] Saguy, S., and Dana, D. (2003): Integrated approach to deep fat frying engineering, nutrition, health and consumer aspects. Journal of Food Engineering, 56: 143-152.

[20] Troncoso, E., and Oedreschi, F. (2009): Modeling water loss and oil uptake during vacuum frying of pre-treated potato slices. LWT-Food Science and Technology, 42 (6): 116-1173.

[21] Dueik, V., Robert, P. and Bouchon, P. (2010): Vacuum frying reduces oil uptake and improves the quality parameters of carrot crisps. Food Chemistry, 119(3): 1143-1149.

[22] Nagadi, M. O., Wang, Y., Adedeji, A. A. and Raghavan, G. S. V. (2009): Effect of microwave pretreatment on mass transfer during deep-fat frying of chicken nugget. LWTFood Science and Technology, 42, 439-440.

[23] Moyano, P. C. and Pedrechi, F. (2006): Kinetics of oil uptake during frying of potato slices: effect of pretreatments. LWT-Food Science and Technology, 39, 285-291.

[24] Debnath, S. Bhat, K. K. and Rastogi, N. K. (2003): Effect of pre-drying on kinetics of moisture loss and oil uptake during deep fat frying of chickpea flour-based snack food. LWTFood Science and Technology, 36, 91-98.

[25] Oils and Fats International (2013): Prices of selected oils. Oct /Nov. Vol. 29, No. 8, Pp 40.

[26] A.O.A.C. (2005): Association of Official Agriculture Chemists. Official Methods of Analysis of 18th ed., D.C. USA. 
[27] Wu, P. F. \& Nawar, W. W. (1986): A technique for monitoring his quality of used frying oils. Journal of the American Oil Chemical Society, 63:1363-1367.

[28] Waltking, A. E. and Wessels, H. (1981): Chromatographic separation of polar and non polar components of frying oils. Journal of the Association of Official Analytical Chemistry, $64,1329-1330$

[29] Gutierrez, F. (1989): Determination de la estabilidade oxidative de acuities de olive virgrnes. Comparacion entre del metodo A. O. M. Y. el metodo Rancimat. Grasas Y Aceities, 40: 1-5.

[30] Carpenter, R. P., Lyon, D. H. and Hasdell, T. A. (2000): Guidelines for Sensory Analysis in Food Product Development and Quality Control. Pp.71-91. Gaithersburg: Aspen Publishers, Inc.

[31] SPSS (2008). SPSS Statistics v. 17.0.1. SPSS Inc., Chicago III.

[32] Ali, A. S., Abdel-Razek, A. G. and Kamil, M. M. (2013): Effect of pre-frying treatments of French fried potatoes to achieve better oil uptake reduction for health and technological aspects. Journal of Applied Sciences Research, 8(10): 5018-5024.

[33] Galoburda, R., Murniece, I. and Karklina, D. (2013): The A3ount of Fat Absorbed by Non-Stored and Stored Potatoes after Frying and Roasting. International Journal of Bioscience, Biochemistry and Bioinformatics, 3 (4): 345348
[34] Boskou, G., Salta, F. N., Chiou, A., Troullidou, E., and Andrikopoulos, N. K. (2006): Content of trans, trans-2,4decadienal in deep-fried and pan-fried potatoes. Eur. J. Lipid Sci. Technol., 108:109-15.

[35] Andres, A., Arguelles, A., Castello, M. L. and Heredia, A. (2013): Mass transfer and volume changes in French fries during air frying. Food Bioprocess Technol., 6: 1917-1924.

[36] Stevenson, S. G., Vaisey-Jenser M and Eskin, N.A.M., 1984. Quality control in the use of deep frying oil. Journal of the American Oil Chemists' Society 61: 1102-1108.

[37] Firestone, D., Stier, R. F. and Blumenthal, M. M. (1991): Regulation of frying fats and oils. Food Technol., 45: 90-94.

[38] Yoon, S. H., Jung, M. Y. and Min, D. B. (1988): Effects of thermally oxidized triglycerides on the oxidative stability of soybean oil. J. Am. Oil Chem. Soc., 65(10):1652-6.

[39] Tseng, Y. C., Moreira, R. G. and Sun, X. (1996): Total frying - use time effects on soybean oil deterioration and on tortilla chip quality. Intl. J. Food Sci. Technol., 31:287-94.

[40] Frega,N., Mozzon, M. and Lercker, G. (1999): Effects of Free Fatty Acids on Oxidative Stability of Vegetable Oil. J. Am. Oil Chem. Soc. 76 (3): 325-329.

[41] Gupta M. K. (2005): Bailey's Industrial Oil and Fat Products, SixthEdition, Six Volume Set. Edited by Fereidoon Shahidi. Copyright \# 2005 John Wiley \& Sons, Inc. 